\title{
The Chisel Test: A Simple, Scalable Learning Activity to Compare Cold Working, Hot Working, and Quench Hardening of Steels
}

\section{Prof. Julia L. Morse, Kansas State University Salina}

Julia Morse is Associate Professor and Program Coordinator for Mechanical Engineering Technology at Kansas State University, K-State Salina. A Certified Manufacturing Engineer (CMfgE) and a Certified Enterprise Integrator (CEI), she teaches lecture and laboratory courses in the areas of computer-aided design, manufacturing and materials, and automation systems. Prof. Morse earned a B.S in Industrial Engineering from the University of Tennessee-Knoxville and an M.S. in Manufacturing Systems Engineering from Auburn University, where she also worked with Auburn Industrial Extension Service. Her work in industry includes engineering experience in quality control, industrial engineering, and design and development functions for automotive parts manufacturers in North Carolina and Germany.

\section{Mark Baugh, Weber State University}

Mark R. Baugh is Associate Professor in Manufacturing Engineering Technology at Weber State University, Ogden, Utah, where he serves as a regional center director for WeldEd and a coordinator of the Miller Electric Regional Training Center. He serves as a national educator trainer for NSF-sponsored WeldEd Workshop "Module 1 - Welding Metallurgy." Recent scholarship focuses on the welding effects on mechanical properties of titanium. He earned an M.S. Industrial Technology, Welding Engineering Technology from Utah State University and a B.S. in Economics from the University of Utah. He formerly served as Associate Director of the Huntsman Environmental Research Center at Utah State University. In 2005 the regional American Welding Society recognized Prof. Baugh with an award for his role in bringing the welding-emphasis bachelor's program to Weber State University. 


\title{
The Chisel Test: A Simple, Scalable Learning Activity to Compare Cold Working, Hot Working, and Quench Hardening of Steels
}

\begin{abstract}
Laboratory experiences with hot and cold working and heat treating typically handle and observe each type of process and its effects separately, carefully preparing specimens and testing and taking data using standard materials testing methods. Observation of results is relatively slow and driven by interpretation of test data. "The Chisel Test" provides a simple introductory comparison which actively engages students in the cold working, hot working, and quench hardening of carbon steel flat bar stock into simple tapered "chisels" and then testing the results by pounding the worked edges against each other. Effects of the process are observed immediately in the context which ultimately matters to an engineer: performance testing.

The active involvement, kinesthetic experience, and visual and auditory effects of hot-working steel create a high-sensory, engaging, memorable learning experience. Equipment is easily accessible and simple requirements allow the working of material to be performed by novices without a dedicated foundry area. Scalability of pre- and post-treatment testing makes variations on the activity applicable to a variety of depths and audiences. According to the needs of the course objectives, performance results can be compared alongside hardness testing data taken the same day, or even followed up with more extensive metallographic preparation and observation of grain structure. Inconsistencies in geometry and integrity of the worked surfaces provide opportunity for students to experience and work through the challenges of obtaining measurements, formulating analysis, and extrapolating conclusions in less-than-ideal conditions.

The activity has been applied as a demonstration activity by welding educators, and as a fuller laboratory exercise in engineering metallurgy or manufacturing process courses at multiple institutions. The effectiveness of the activity is assessed through observation of student participation during the activity, and from direct evaluation of student accomplishment of related learning objectives on exams and lab reports.
\end{abstract}

\section{Introduction}

The "Chisel Test" is a simple activity designed to involve students in hands-on deformation of steel using cold-working, hot-working, and quenching techniques. Steel strap is hammered into wide "chisel" forms and then the properties of the resulting worked material is compared by hammering the chisels against each other at right angles.

The activity has been successfully applied in various settings. It is a powerful demonstration without the use of accompanying data, other than the visual comparison of which technique forms the chisel which demonstrates superior strength to the others. 
In this paper we focus on the application within a sophomore-level materials and metallurgy course. The initial desire to pursue this activity has been primarily in the hope that it would increase general student engagement and experiential learning in the related metallurgical topics. Previous experience with video assignments in this course had revealed increased student interest in discussing course content related to sword-making and historical blacksmithing applications. It was hoped that students would find a similar connection with the metalworking activities.

It was further hoped that participation in the activity would help students better to increase student connection between general experience and more detailed concepts and data. To that end, hardness data, taken before and after the deformation processes, was also collected, making the demonstration into an experimental laboratory activity.

\section{Related Approaches in the Literature}

The history of Engineering Technology education is built upon incorporation of such practical experience into the class and lab experience. Active learning techniques are expected in materials and engineering education. Medlin et. al. ${ }^{1}$ have successfully applied an extensive series of "blacksmithing" processing and testing laboratories to solidify learning of materials objectives. Palmer ${ }^{2}$ promoted a more traditional series of materials heat treating and testing labs and a separate cold working experiment with copper wire to provide student experience with various strengthening mechanisms. Magna $^{3}$ presented an experiment to take brass or other material through cold working (through rolling at differing percents of reduction in thickness) and then recrystallization. Measurements are tracked through hardness and tensile testing.

The novelty in this class or lab experience is not in its hands-on approach, but in the unique way it provides a very quick and immediate return on practical results that can be easily perceived, comparing different mechanisms (processing) applied to the same material without careful measurement or data collection and analysis. This approach attempted to capitalize on the energy of student participation in highly kinesthetic activity involving multiple senses. A small amount of data collection added to the activity intended to back up the simple observation of the "Chisel Challenge" results.

\section{Approach of this Activity}

The experiment can be performed with minimal equipment in a welding area or possibly outside. Equipment includes:

- Oxyfuel heating torch (rosebud or equivalent)

- Water quench tank or bucket

- Heavy duty vise

- Anvil

- 4-lb or heavier hammer

- Vice Grips or pliers

- Personal safety equipment for oxytorch use: safety glasses, shade 5 gutting goggles, ear plugs, gloves, appropriate clothing 


\section{General Procedure, Parts A \& B}

\section{Part A - Initial Hardness Testing}

Use the Rockwell Hardness Tester to take initial hardness readings on each of three specimens (carbon steel, 1.5 to 2 inches wide, 3/16 inch thick, minimum 3 inches long). Test a series of positions at $1 / 8$ " intervals from the end to be worked into a chisel. Assuming readings seem consistent, you may stop after 3 readings each.

\section{Part B -Two Hot-Worked Chisels (“A” - Air Cooled, “Q” - Quenched)}

1. Heat one end of each piece until orange in color $\left(\approx 1800\right.$ to $\left.2000^{\circ} \mathrm{F}\right)$, as depicted in Figure 1A.

2. Work the chisel edge into the specimens by hammering them at the anvil. Hold the cool end with pliers and hammer the heated end flat. While hammering, rotate the plates so that each side is flattened.

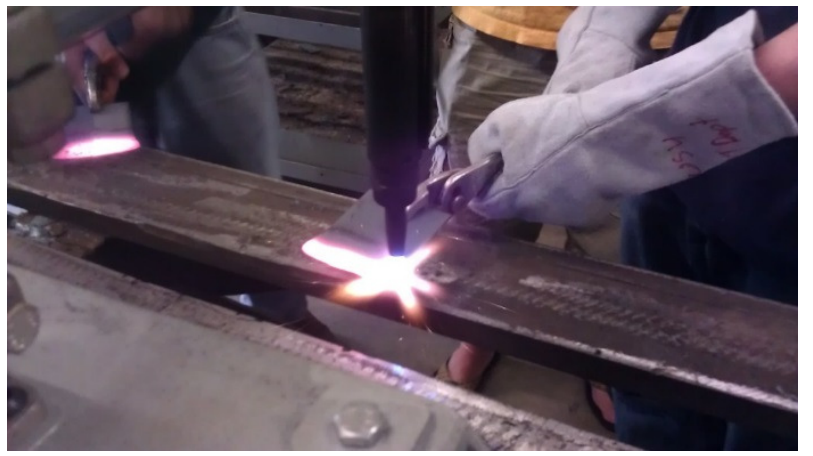

Figure 1A. Heating the specimen.

3. Repeat the previous two steps as necessary until a general sharp chisel shape is produced. The edges should be reasonably uniform in thickness $(\approx 1 / 32$ in thick at the edge) across the width of the sample, as well as in comparison to each other.

4. Reheat both of the newly formed surfaces orange heat ( $\approx 1800$ to $\left.2000^{\circ} \mathrm{F}\right)$.

5. Follow the cooling procedure specified for each:

a. For the "Q" specimen, rapidly quench in water immediately upon removal of heat.

b. For the "A" specimen, allow it to cool slowly on firebrick (Figure 1B) or hold in pliers and air cool.

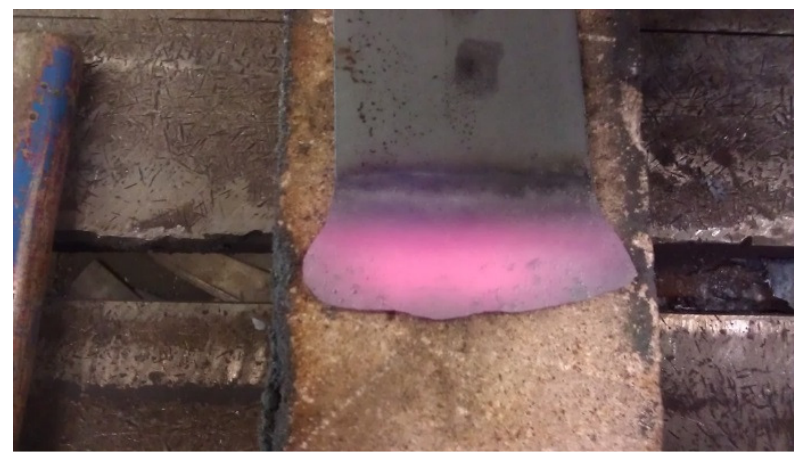

Figure 1B. Air-cooling "A" on firebrick.

6. Mark the mark the samples " $Q$ " and " $A$ " with the paint marker, if this has not been done already.

Figure 1. Chisel Test Procedure, Part A \& B 


\section{General Procedure, Parts C through E}

\section{Part C - Cold-Worked Chisel ("CW")}

1. Mark the third specimen "CW".

2. Form the chisel shape without applied heat (Figure 2A). Use larger hammers, if required, to apply the enough stress to exceed the material yield strength at room temperature.

\section{Part D - Performance-Testing the Chisels}

1. Test each combination of the chisels as follows:

a. Place one of the specimens in the heavy-duty vise (in the welding area, not the machining area) and firmly secure the part.

b. Using pliers or vise grips, hold the second sample at right angles to the vise-secured samples (Figure 2B). A second lab team member hammers 5 blows of similar force to drive the samples into each other.

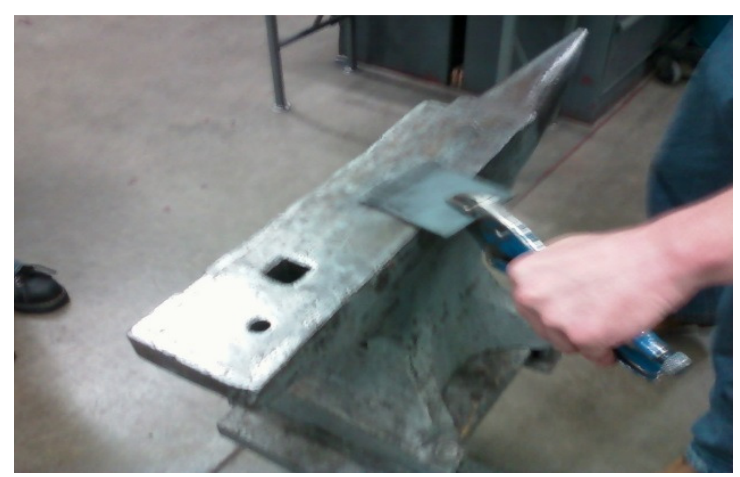

Figure 2A. Cold-working at the anvil.

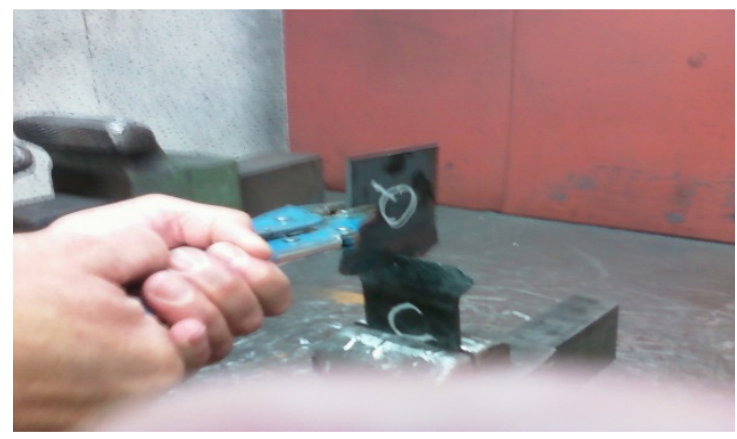

Figure 2B. Chisel-testing at the heavy-duty vise.

\section{Data Collection}

a. Observe which parts yield and split which other part(s). Measure the yield length (of the indentation made by the winning chisel).

b. Take Rockwell hardness measurements at $1 / 8$ inch (or less) increments from the chisel edge up to and into the undeformed material (until the readings no longer change, if practical).

\section{Part E - Reheating the Quenched and Cold-Worked Parts}

1. If time permits, reheat the winning chisel to orange $\left(\approx 1800\right.$ to $\left.2000^{\circ} \mathrm{F}\right)$ and allow both to air-cool on the firebrick.

2. Re-test the re-heated and air-cooled part against the second-place tool.

3. Reheat and cool the second-place tool.

4. Take both reheated and air-cooled parts to the hardness tester to check the effects of reheating and air-cooling on hardness.

Figure 2. Chisel Test Procedure, Parts $\mathrm{C}$ through E. 
The procedure outlined in Figures 1 and 2 is the activity approach that was evaluated within a sophomore physical materials and metallurgy course for engineering technology students. In addition to the simple "Chisel Challenge," observation of material hardness using a standard Rockwell testing machine was made before and after forming the chisels.

Teaching suggestions include:

1. Have students work in groups.

2. Assign each group a test piece.

3. Try to make sure the sharpened edge is the same width on each sample.

4. Help them to understand what is happening inside the metal that makes it stronger.

5. Help them to understand that if heat is applied, (like from welding) it would damage the strength.

6. Discuss which is stronger: The heat treated sample or the cold worked sample?

A suggested instructional handout is appended to this paper.

Figure 3 displays the appearance of typical "chisel" parts after they have been pitted against each other. The annealed ("A") and cold-worked ("CW") chisels bear the indentations left by the quench-hardened chisel ("Q").

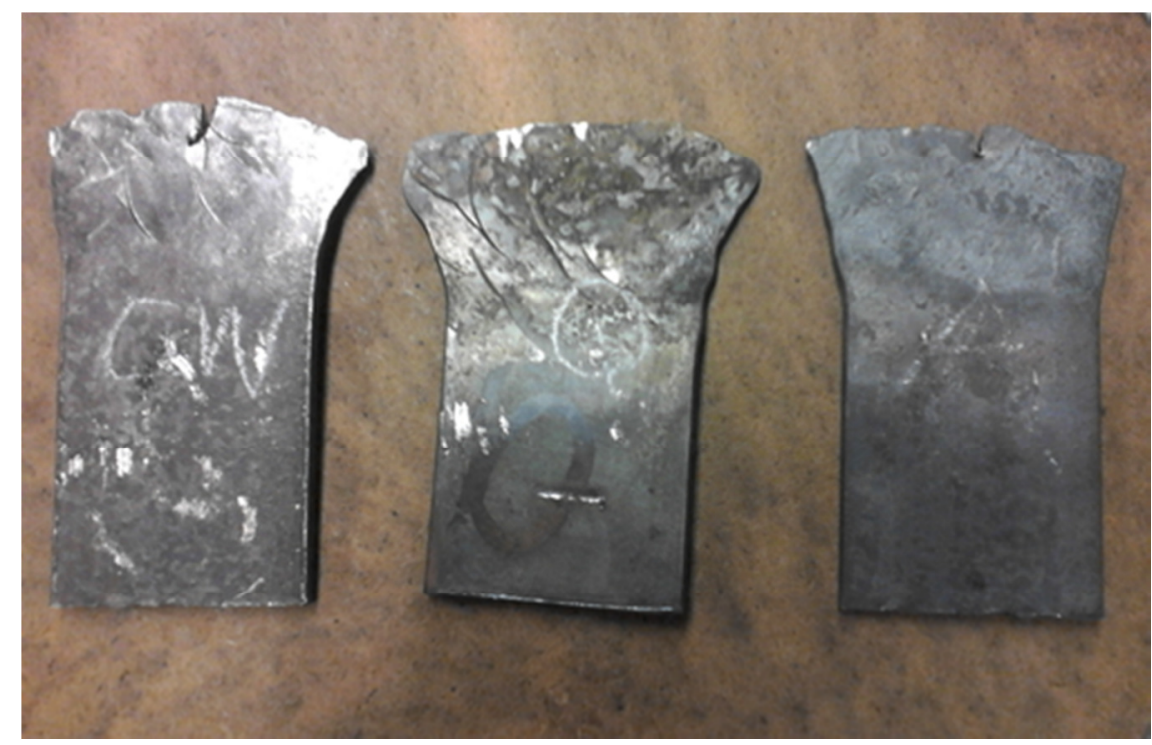

Figure 3. Finished Chisel Parts

\section{Results}

The activity succeeded in being engaging to the students. Students enjoyed the activity and were attentive to the process. Students got a great visual, kinesthetic sense of treatment possibilities, and their participation made them cognizant of the variability of input variables they were attempting to impart and the fact that the outcomes varied. 
However, student lab reports showed that the main result gleaned was that "quenching won"that hot working with quenching produced a harder material. The importance of relative lessons of air-cooling and cold working were often overlooked in the final reports, even though hardness data was collected, reported in tables, and comparative line graphs and conclusions required.

When we attempted to stop and take hardness tests before the "chisel challenge," this seemed to reduce interest in the activity, having lost some of the focus and interest built up during the novelty of heating and working the chisels into shape.

Hardness test results were not visually compiled and displayed during the activity itself, and students did not put as much attention in the development of results after-the-fact except as necessary to follow instructions (and some not even then).

Additionally, the variability experienced during the activity is a mixed blessing. It was thought to provide good experience with real-life contributors to variation and measurement difficulties. However, some variability in results had a tendency to cloud student recognition of the bigpicture expectations of the experiment. For example, brittle failure of the quenched chisel sometimes confused students when comparing its strength with the other specimens. Variation in the hammered thickness of the chisel edges also cause unexpected results. Hardness readings had been intended to help lend clarity, but difficulties in getting consistent hardness readings on misshapen hammered surfaces or amid scale sometimes caused confusion regarding hardness results. Some students were also still confused by hardness results that straddled the B and C hardness scales.

While the initial lab reports did not return the clarity of understanding to be hoped for, there is an indication that the initial demonstration during introduction to methods of hardening metals may have assisted students in developing an overall framework of understanding for the material-along with a few other small improvements in course delivery. Overall, exam scores over this portion of the course material have improved slightly during the two years the Chisel Test lab has been conducted as a part of the course, as demonstrated in Figure 4.

\section{Conclusions}

Hardness data was added to the simpler exercise in an attempt to provide a clearer picture of the results, but it seems to have taken away from the power and simplicity of a simple hands-on demonstration experience.

The activity is valuable in gaining attention at first exposure to different hardening (or softening) mechanisms, but it may have more impact to do just the quick "chisel challenge" demonstration for a first exposure, and saving more careful examination of hardness data for a separate lab activity. The initial hardnesses could be tested ahead of time and then saved and provided for students later, when a separate activity might dig deeper by testing post-worked hardness.

Alternatively, the activity could be developed to better focus students on data as it is being collected and developed. For example, specific worksheets could require teams to predict and 


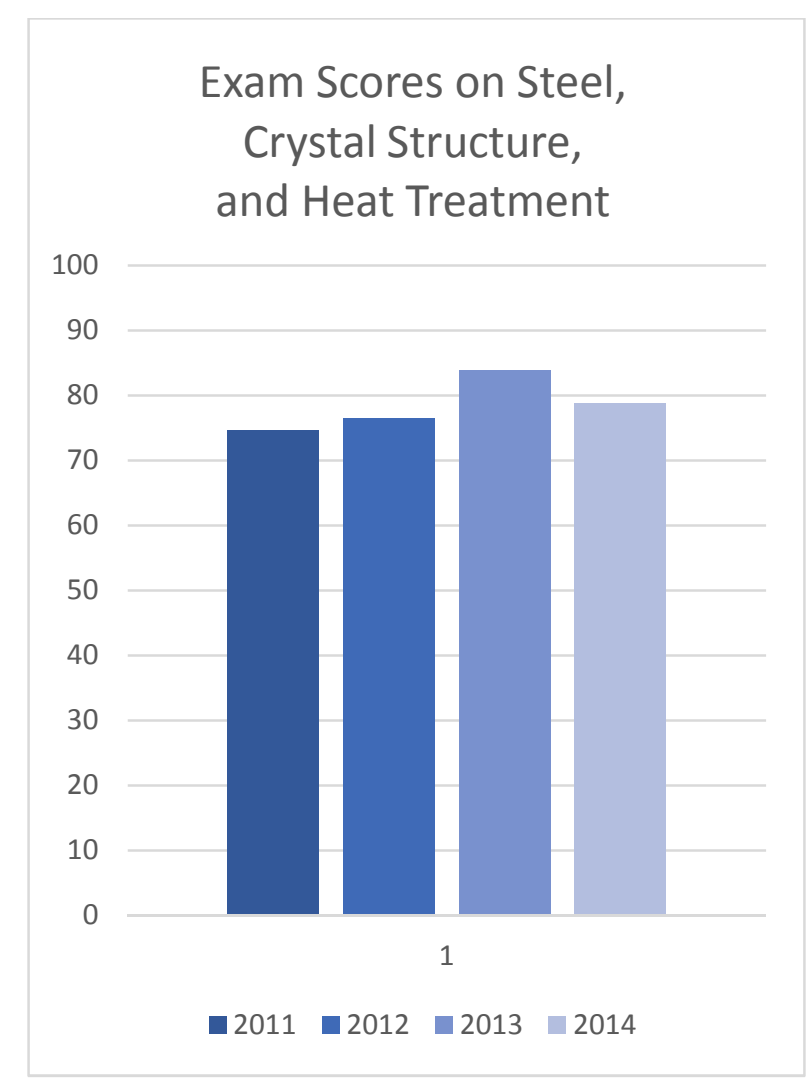

Figure 4. Exam scores showing some improvement in the last two years, when this activity has been implemented.

draw conclusions along the way - and check them on their assumptions. Or instructor dialog at the activity could include plotting and sketching graphs or visuals as the data is developed together, in a sort of play-by-play.

Regardless of student absorption of the finer details, the activity has been successful in providing strong visual pictures of processing strategies that are not easily forgotten by the students. The activity early in the semester built up an expectation of energy and enthusiasm expected for future lab activities. Student attitudes and, to a certain extent, exam scores, indicate the value that involve students in the production of the properties of their materials - particularly when it involves flame and hammers.

\section{Bibliography}

1. Medlin, Dana et. al., "Improved Materials Science Understanding with Blacksmithing," Proceedings of the 2009 American Society for Engineering Education Annual Conference \& Exposition," 2009.

2. Palmer, Mark A., "Two Processing-Structure-Property Laboratory Activities to Culminate a Course in Engineering Materials, Proceedings of the 2005 American Society for Engineering Education Annual Conference \& Exposition,” 2005. 
3. Magda, Daniel. "Hands-on Lab Demonstration to Teach How Mechanical Properties Change Due to Cold Working and Recrystallization," Proceedings of the 2009 American Society for Engineering Education Annual Conference \& Exposition," 2009. 


\section{Lab Handout - The Chisel Test}

\section{Topics covered:}

Changing the structure of low carbon steel changes it properties Cold working of low carbon steel

Hot working of low carbon steel

Quench hardening of low carbon steel

Hardness measurements and comparisons

\section{Materials for Lab:}

3 pieces per group or individual of ASTM A36 Hot rolled steel, $3 / 16$ in. thick, 1.5 to 2.0 in. wide, 3 to 4 inches long

\section{Equipment for Lab:}

Oxy-fuel heating torch (rosebud or equivalent)

Water Quench tank or bucket

Heavy duty vise

Anvil

4-Ib or heavier hammer

Vise grips or pliers

Metal letter stamps

Fire brick

Optional: Hardness measurement method

Rockwell hardness tester, B scale

\section{PPE}

Welding gloves

Ear plugs

Safety glasses

Shade 5 cutting goggles

Leathers or fire resistant jacket 


\section{Part A - Hardness Testing and Marking}

1. If a Rockwell hardness tester is available:

Using the " $\mathrm{B}$ " scale (HRB), take three hardness measurements on each specimen as depicted by the circles on the following figure:

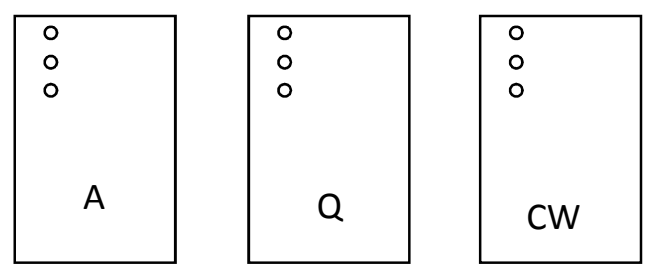

Average these readings and record as: Initial hardness

2. Mark each specimen with metal stamps:

One with an " $A$ " which will be air cooled.

One with a " $Q$ " that will be quenched.

One with an "CW" that will be cold worked.

\section{Part B - Two Hot Worked Chisels ("A" - Air Cooled, "Q" - Quenched)}

1. Take the " $A$ " specimen and the " $Q$ " specimen and continue.

2. Wearing gloves, using a torch, heat one end of each specimen by holding one end with vise grips or pliers, until there is about one inch of orange on the heated end. ( 1800 to $2000^{\circ} \mathrm{F}$ )

3. Quickly move the heated specimen to the anvil, still holding it with the pliers. Make sure you have safety glasses and ear plugs. Then using the hammer begin to pound the heated end into a chisel shape. When the specimen is no longer orange stop hammering.

4. Re-heat the specimen until orange again, then turn over the specimen and hammer the other side.

5. Continue with this process until each chisel specimen has about a 1/32 edge on it.

6. Re-Heat each specimen a final time until it is bright orange.

7. Take the specimen marked with a " $Q$ " and immediately quench it in the water. Be sure to move it around in the water to prevent the steam from insulating it.

8. After it is cool remove it from the water and save it for testing.

9. Take the " $A$ " specimen that has been heated orange and place it on a fire brick or leave it suspended in the vise grips. (Letting it rest on metal will help it cool too fast.)

10. Leave the " $A$ " specimen there until it cools down to room temperature.

\section{Part C - Cold Worked Chisel ("CW")}

1. Take the specimen marked " $\mathrm{CW}$ " and grip it on one end with the vise grips or pliers.

2. Place it on the anvil and begin to hammer it into a chisel (no heat is applied to this specimen)

3. Turn the part over and apply hammering equal on each side until it is formed into a chisel shape, with the edge approximately $1 / 32$ inch, similar to the other specimens. If the specimen gets hot from the cold working, cool it off in water. Note: Some cracks may be formed in the edge of this specimen, this is normal. 


\section{Part D - Performance - Testing the Chisels}

1. Take each chisel specimen and perform a hardness test on each specimen. Start as close as possible to the chisel edge, then take hardness measurements back in $1 / 8$ inch increments until the hardness number no longer changes.

2. Place the "A" Air Cooled specimen in a heavy duty vise, a block may be put under the specimen to keep it from slipping.

3. Take the "QW" - Quenched specimen and grip it with vise grips. Place it at 90 degrees to the one in the vise (chisel to chisel)

4. Have another person hit the back of the "QW" chisel with 5 even stokes. Try not to let the chisels move into a different position during the strokes.

5. Mark the spot where the two chisels met. Measure the depth of each of the cuts that the chisels made in each other. Record this information. ("QW" vs. " $A$ ") Depth of cut in " $A$ " and "QW" (Teaching point: Why is the cut deeper in the " $A$ " specimen?)

6. With the " $A$ " chisel still in the vise, take the " $C W$ " specimen in the vise grips and place it on an uncut spot on the " $A$ " chisel at 90 degrees as before. (Pick a spot on the "CW" chisel that is not split)

7. Have the same person hit the back of the "CW" chisel with similar 5 even strokes.

8. Mark the spots where the two met and measure and record the depth of the cuts. ("CW" vs. " $A$ ") Depth of cut in " $A$ " and "CW" (Teaching point: Why is the cut deeper in the " $A$ " specimen?)

Part E - Optional Testing

"CW" vs. " $Q$ "

1. Using the same technique as before, drive the " $C W$ " chisel into the " $Q$ " sample.

2. Mark the spots where the two met and measure and record the depth of the cuts. ("CW" vs. " $Q$ ") depth of cut in " $Q$ " and "CW" (Teaching point: Which specimen has a deeper cut in it?)

\section{Reheating " $\mathrm{CW}$ and " $\mathrm{Q}$ ” Specimens}

1. Reheat the wining chisel to orange (approximately 1800 to $2000^{\circ} \mathrm{F}$ ) and allow it to cool on the firebrick.

2. Re-Test the reheated and air cooled part against the second place specimen.

3. Reheat and cool the second place specimen.

4. Take both reheated and air cooled specimens to the hardness tester to check the effects of reheating and air cooling on hardness.

\section{Conclusions}

1. Rate in order of hardness (less cut depth) " $Q$ ", "CW", " $A$ ", Reheated " $Q$ ", Reheated "CW."

2. Which method of strengthening steel provides the hardest chisel?

3. Rate Rockwell measurements to see if the results match the chisel test. 